\title{
Nonlinear Pedagogy Underpins Intrinsic Motivation in Sports Coaching
}

\author{
Ian Renshaw ${ }^{*, 1,2}$, Anthony R. Oldham ${ }^{3}$ and Mark Bawden ${ }^{4}$ \\ ${ }^{1}$ Institute of Health and Biomedical Innovation, Queensland University of Technology, Australia \\ ${ }^{2}$ School of Exercise \& Nutrition Sciences, Queensland University of Technology, Brisbane, Australia \\ ${ }^{3}$ Coach Development Centre, Auckland University of Technology, Auckland, New Zealand \\ ${ }^{4}$ Metaphorics Performance Consultants \& English Institute of Sport, Sheffield, England
}

\begin{abstract}
A key challenge for sports coaches is to provide performers with learning environments that result in sustainable motivation. In this paper, we will demonstrate that programmes based around the principles of Nonlinear Pedagogy can support the three basic psychological needs that underpin self-determined motivation. Coaches can therefore ensure that practice sessions provide for intrinsic motivation with its associated motivational and emotional benefits.
\end{abstract}

Keywords: Nonlinear pedagogy, self-determination theory, sports coaching, constraints, motivation.

\section{NONLINEAR PEDAGOGY AND SELF DETERMINA- TION THEORY}

The progression of performers towards a state of expertise is commonly facilitated through repetitive practice or "drilling" by coaches, an approach grounded in the principles of deliberate practice [1]. Drill based practice sets out a significant motivational problem for performers and coaches alike in that it involves large amounts of repetition which can be both monotonous and boring [2-4,]. This situation is often reflected in the language of expertise development which talks of the need for sacrifice and struggle to become an expert in sport (or music, art, academia). As a result, coaches often resort to a range of behaviourist-type strategies including verbal exhortation, punishment, bribery (disguised as 'rewards') or threats to promote high levels of motivation in athletes. Viewed from a Cognitive Evaluation Theory perspective [5] a significant down-side of these approaches is that performers become more extrinsically motivated and consequently suffer diminished internal motives towards a given pursuit. Extrinsically motivated performers are likely to be those with low levels of engagement only practicing in the presences of a coach, or significant other incentives.

Here we argue that coaches can facilitate the development of intrinsic motivation by basing learning design on the principles of Nonlinear Pedagogy (NLP). Elsewhere we have demonstrated how a constraints-led perspective can substantiate a platform for this new framework through its adoption of a fundamental understanding that the appropriate level of analysis is the interaction of the individual and the environment [6-10]. There is now extensive evidence to demonstrate that adopting NLP meets the skill acquisition needs of individuals, but so far little work has been undertaken exploring potential advantages in terms of meeting the psychological

*Address correspondence to this author at the School of Exercise \& Nutrition Sciences Queensland University of Technology Victoria Park Road Kelvin Grove 4059: Tel: +61 73138 5828; Fax: +61 73138 3980;

E-mail: i.renshaw@qut.edu.au needs of performers. A starting point would be a motivational theory that is as strongly focussed on the needs of the individual as NLP. One such theory is Self-Determination Theory (SDT) [5] with its concomitant focus on meeting individual needs of in terms of perceptions of competence, relatedness and autonomy. In this paper, we will show how practice design along with the delivery of instruction and feedback requires careful consideration so that practice is based on the skill acquisition and psychological needs of the individual. Through practical exemplars we demonstrate how the concepts and ideas of SDT and in particular basic psychological needs as postulated by Deci \& Ryan [5], can be met by adopting a more hands-off approach to coaching advocated by a constraint-led approach. More beneficial motivational outcomes driven by SDT can be embedded into programme design by employing this approach.

\section{SELF DETERMINATION}

Self Determination Theory (SDT) is a meta-theory that provides a broad framework for the study of motivation, development and well-being [5, 11]. It is underpinned by the postulate of three basic psychological needs; Autonomy, Competence and Relatedness. Relatedness concerns the need to feel connected, involved, supported and consequently experience satisfying inter-personal relationships [12, 13]. Organismic and evolutionary theorists might argue in support of the desire to affiliate and share actions with others in so far as "those who don't act with the herd get eaten first" or are at greatest risk. What is proposed in this paper goes beyond this in that the surrounding context and the approval of others provide a framework from which competence may be explored in diverse ways. Deci \& Ryan [14] also point out that actions that undermine autonomy may also have an impact on relatedness. Thus, a coach that starts praising a behaviour previously pursued for intrinsic reasons may be seen as lacking understanding, authenticity or congruent motives. Competence reflects a belief in one's abilities and capacity to control outcomes [15,16]. According to Deci \& Ryan [5] 
competence is linked strongly with feelings of autonomy as explored in Cognitive Evaluation Theory (CET - Deci \& Ryan, $[17,18]$. According to CET optimal intrinsic motivation emerges from conditions where the need for competence and autonomy are met. This draws attention to practice and play where the learner can quickly perceive personally meaningful goals and identify related instances of success. Recent research into the thwarting of psychological needs by Bartholomew and colleagues [19] highlighted that competence can be undermined by unrealistic expectations and lack of opportunities to fulfil potential provided by others. This sets out important conditions for the development of competence in so far as it points to a requirement for optimal personal challenge. Goal setting literature supports this view with moderate goals delivering the greatest performance effects [20]. Determining optimal challenge is as much the task of the performer as it is the coach, and as we describe below, NLP with its "hands off" philosophy leaves it to the learner to set all but the broadest of goals. Coaches adhering to this approach are left to constrain learning environments in a way that matches the learning threshold of the learner (see also [21]). Autonomy represents the desire to express choice and not to feel controlled or compelled to do something [22, 23]. It also concerns the extent to which people genuinely feel that the forces propelling their behaviours are in agreement with their personal values. As Deci and Ryan [5] put it, the issue is whether they are pawns to those forces, or, alternatively, perceive the forces as being valuable, helpful, and congruent sources of information that support their initiative.

As we will discuss later, amongst SDT's assumptions are that human beings are self-organising systems oriented towards growth, development and integrated functioning [5, 10, 24]. An important feature of SDT when considering its role in skill acquisition is how the innate goal of satisfying the basic psychological needs of competence, relatedness and autonomy fits with external goals commensurate with enhancing sport performance. This aligns well with the idea that it is not only the skill that matters but how it is taught. In learning environments where these psychological needs are met, adaptive self-determined motives emerge; where they are not met individuals become frustrated and maladaptive motives, behaviour and movement patterns emerge [5, 25]. Thus, the way in which a tennis serve is coached will affect its expression as a movement skill along with any resulting emotions and motives. While this is not a unique idea amongst motivational theories, what is particularly appealing about the SDT approach is that it is underpinned by a theory of individual needs. Individual needs can be seen as constraints that need to be considered within a NLP framework. Deci \& Ryan [5] argue that people will act in order to meet their basic need for Competence, Autonomy and Relatedness and therefore is an important goal for any programme directed towards expertise. Pursuit of Autonomy, Competence and Relatedness and the intrinsic motivation resulting from their satisfaction can be seen as an energising individual constraint that encourages effort, persistence and problem solving with respect to goal tasks. When considered in isolation, or as a whole, it should be clear that these are organismic constraints worthy of detailed consideration by practitioners.
Motives that fail to meet psychological needs are characteristically controlling, over challenging and prescriptive, characteristics commonly shared with drill-based perfect model approaches to skill. Thus, any child or athlete centred approach that seeks to encourage participation must be underpinned by a philosophy and pedagogy that meets these needs and avoids these conditions. Chow and colleagues [9, 26] have discussed NLP and this approach is particularly appealing in that it underpins a learner centred approach and the emergence of skills rather than the deliberate description and drilling of technique. Below we will introduce NLP and then go onto show how this pedagogical approach corresponds strongly with the psychological needs outlined by Deci \& Ryan [5].

\section{NONLINEAR PEDAGOGY}

Nonlinear pedagogy has its origins in Ecological Psychology and Dynamical Systems Theory and is an approach to coaching practice that is 'based on application of the concepts and tools of nonlinear dynamics' [8]. In this respect, humans exhibit key characteristics observed in other nonlinear dynamical systems in nature, e.g., openness to surrounding information flows, capacity for self-organisation under constraints, stabilities and instabilities and capacity for state phase transitions providing a foundation for the emergence of creative and adaptive behaviours [27].

The foundation of NLP is the manipulation of key interacting individual, task and environmental constraints acting on learners to facilitate the emergence of functional information-movement couplings that satisfy these constraints $[8$, $10,28]$. Constraints are boundaries that shape a learner's movement-organisation, cognitions and decision-making processes [29]. Newell [28] indicates that there are three categories of constraints, 1 . Individual performer constraints include structural (e.g. height, arm length) and functional (e.g. cognitions and emotions) constraints. 2. Environmental constraints include physical and cultural constraints. Physical environmental constraints include weather conditions, practice facilities and the access to play areas when growing up. Cultural constraints include family support and networks, school values in terms of sport and academic achievement and media representation of a specific sport. 3. Task constraints include specific rules of a sport, instructional constraints, such as verbal instructions, demonstrations, types of feedback as well as practice methods such as the use of task simplification or task decomposition (see later). These key constraints act interactively to underpin the emergence of self-organized movement patterns. For an extensive review of NLP and its application for coaches and teachers, the reader is pointed towards Renshaw [6, 7, 30]. Adopting a NLP has some important implications in terms of the psychological impact on performers. Below we introduce some of the key underpinning concepts in NLP and show how they implicitly meet the self-determining needs of athletes.

Self organisation under constraints. Adopting the view that movement behaviours are predicated on the interaction of individual, environmental and task constraints gives sports coaches some significant advantages. First, the concept of self organisation emphasises the need for practice that adopts the principle of 'repetition without repetition' [31]. In this 
approach, coaches design representative practice tasks that allow individuals time and space to explore and discover coordination patterns and make decisions that are most appropriate for their unique constraints [10]. Repetition without repetition means that performers develop more functionally variable movement patterns, which is also supported by the idea of degeneracy, the capability of structurally distinct parts of complex movement systems to achieve different outcomes in varying contexts [10]. Opportunities to develop functional variability are essential for skilled performers so that they can learn to adapt to changes in the performance environment. For example, cricket matches that last 5 days require players to adapt to significant changes in the environmental and task conditions over the time frame of the match. A second consequence of adopting a NLP is the impact it has on coaching behaviours. The concept of degeneracy means there is no need to prescribe movement solutions in an attempt to replicate optimal movement solutions, meaning that coaches do not have to give prescriptive, explicit instructions or error focused feedback. As most natural learning takes place through subconscious processes [31, 32] there is no requirement to force learner to switch to conscious control of actions as telling a performer how a task should be performed can lead to performance disruption and de-automisation [32]. Nonlinear pedagogy supports the view that coaches should provide instructions that simply tell players what to do (e.g., hit the ball between the cones). This has some important consequences for performers. On the level of skill acquisition, by encouraging exploration and use of implicit learning strategies, coaches allow subconscious intrinsic self organisation processes to be harnessed by learners (see [33, 34]). On a motivational level, adopting NLP allows individuals to explore in practice to find their own optimal solutions to performance problems, meaning that performer's perceptions of competence and autonomy are not constantly threatened by being told what to do to in order to perform the task in the 'right way'. In fact, perceptions of competence and autonomy are more likely to be enhanced as individuals are more in control of the process of learning and more likely to find ways to achieve that are matched with their action capabilities. Finally, because the nature of the interactions between coach and athlete in NLP are athlete-centred, the perceptions of relatedness between the dyad are likely to be enhanced.

Perception: action coupling. The mutual interdependence of environmental information and action implies that performers' perceptual and action systems should not be developed separately during training and practice tasks by coaches [6]. Ensuring that perception and action are developed in unison requires coaches to assess the degree to which practice reflects performance. This is achieved by sampling the environment in order to determine whether specifying information sources available in competition are similarly present in practice. This key theoretical principle highlights the importance of making practice design representative of the 'real' performance (see [35] for a detailed discussion of representative learning design). Carefully sampling practice environments to ensure they contain key information sources present in competition environments means that coaches should use task simplification (preserving the key information sources but simplifying the task), rather than task decomposition (de- coupling the relevant information making it more difficult for learner to perform the action). Failure to maintain key information sources in practice risks 'accidentally' facilitating the development of movement solutions around inappropriate information sources and threatens perceptions of competence in competition. A good exemplar to illustrate this point is batting against ball projection machines. Recent research has demonstrated that when facing bowling machines, cricket batters delayed bat-swing and shortened the forward step while batters sample more of the ball flight before acting [36]. The use of ball projection machines also leads to a different pattern of behaviour in terms of visual search before ball release [37]. When facing real bowlers, expert batters search for early cues from the run-up and bowling actions of bowlers to help determine the characteristics of the upcoming delivery [37-39]. Therefore practicing against a ball projection machine as opposed to a real bowler, leads to self-organisation of very different movements that are potentially less suited to the demands of the real game, and can result in performance decrements and accompanying loss of self-efficacy [30]. Consequently, adopting representative learning design allied with task simplification is more likely to lead to enhanced perceptions of competence as it provides athletes with numerous opportunities to learn to couple perceptions to actions in realistic conditions that mirror the psychological as well as perceptual information present in competitive environments.

\section{The Learner as a Dynamic System: Harnessing Stability and Instability}

Skill acquisition can be viewed as a process of dynamic stability and for practitioners it is important to understand that athletes are variously sensitive to change as a result of controlled and uncontrolled changes in environmentindividual interactions. As such, changes in individual structural or functional constraints, or performance environments over different time-scales can impact on performance and the ongoing psychology of the perfomer. Consequently, crucial to designing individualized development programmes is identifying when behavioral patterns are stable or unstable and more open to change [40]. In this co-adaptive model, phase transitions (e.g., sudden changes) in system behaviour are most prevalent when learners are in metastable regions when conditions are equally poised on the edge of stability and instability [41]. Coaches can deliberately create instability in practice environments by exposing individuals to high levels of variability forcing exploration of their boundaries. This leads to the development of highly adaptable performers who can choose from a range of stable functional movement patterns [42]. While the long-term effects of adopting such practice methods is likely to enhance confidence as it expands the range of solutions available to the athlete, it is important to understand when and when not to implement activities that lead to instabilities. For example, stability in practice would be most important in the period immediately before major competition events in order to maintain or build the confidence of performers [6].

In summary, constraint-led coaching requires a focus on the needs of the individual as the unique interaction of personal, environmental and task constraints leads to the rejection of a common optimal movement model in sport. This 
point is crucial to the coaching process as it suggests a new role for instruction, demonstration, feedback and consequently the psychology of learning. The key idea that information and action act to constrain each other provides a basis for representative learning design [43]. Finally, because the human movement system is degenerate (able to organise itself in many different ways to achieve the same outcome) and the environment is dynamic (constantly requires adaptation to changing constraints), coaches need to provide variable practice opportunities for performers. This variability will enable the emergence of multiple solutions to achieve movement goals and in turn develop intelligent, motivated, highly adaptive individuals who are able to cope with the predictable and unpredictable changes in sports performance landscapes. As we now go onto explain, the same learning design can be used to promote key psychological needs including competence, autonomy and relatedness. Each exemplar activity has been developed based on careful application of the theoretical and practical concepts underpinning NLP and SDT.

\section{EMBEDDING AUTONOMY, COMPETENCE AND RELATEDNESS INTO CONSTRAINT-LED COACH- ING}

In the sections below, we deliberately focus on demonstrating how relatedness competence or autonomy can be enhanced via NLP. This is done simply to aid clarity and the reader is encouraged to explore the links between the focus topic and the other key areas of SDT. We initially focus on relatedness as SDT and NLP have the individual as their focus and this acts to define the nature of the coach-athlete relationship and consequently underpins the coaching process (see [6]).

\section{Enhancing Relatedness Through Nonlinear Pedagogy}

Constraints-led approaches, Nonlinear Pedagogy and Dynamical Systems Theory [6-9] are particularly appealing with respect to exploring relatedness. They underpin a learner-centred approach and focus on emergence of skills rather than the deliberate description and drilling of technique along with correction of errors that come bundled into this method. The NLP approach to developing skill includes the use of modified interactive practice, questioning and cooperative learning. These aspects correspond strongly with relatedness as outlined by Deci \& Ryan [5]. For example, the proximity of learners and degree of interaction demanded by that context will encourage greater interpersonal exchange which in turn should lead to greater feelings of relatedness. Similarly, because practice requires performers to work together to solve problems, the role of the coach is changed to one that supports and guides rather than directs. Intrinsic to the nature of well-constructed games should be the ability for learners to generate their own feedback, reducing what may be seen as a punitive role for coaches which acts negatively on the coach-athlete relationship.

The nature of the coach-athlete relationship is one of the foundation stones upon which the coaching process is built [44] and successful relationships have been shown to be associated with success, athlete satisfaction and team cohesion (see [45]). Conversely, less effective relationships are asso- ciated with conflict along with a lack of trust, communication and respect between coach and athlete (e.g. [46]). Fundamental to the qualitative structure of the coach-athlete relationship is the coaching culture put in place by the coach. As discussed in the earlier section introducing NLP, when coaches create a culture typified by 'practice makes perfect'; the associated corrective feedback and perceived lack of success can lead to perceptions of coach pressure and a fear of failure in young athletes. Fear of failure has negative consequences for the relationship between coach and athlete resulting in avoidance goals to protect self-esteem [45]. Performers typically play safe when they fear negative reactions and avoid risk taking that could lead to making mistakes. This 'climate of fear' [47] can lead to negative affect and an accompanying drop in motivation levels. For young athletes it can also result in a complete breakdown in the relationship as they consider dropping out in an attempt to defend perceptions of their ability and competence, their social value, and hence their sense of worth [45]. Chappell in [30, p.165] highlights the problems of coaches focusing on the acquisition of optimal movement solutions when he says:

All that the individual hears [in a traditional approach] is that 'I'm no good' and it actually reinforces what they already think anyway; that 'I'm no good, I can't do this', you know-'I'm not good enough, I'm a failure'; all of the negative impacts that we're trying to avoid.

In contrast, adopting a constraint-led approach leads to a more functional relationship where responsibility for developing performance is shared. This modification changes the power dynamic as the role of the coach moves from someone who prescribes solutions and 'judges' performance to one who has more of an advisory or 'mentoring' role. Chappell continues [30]:

I think ... it lessens the danger of the breakdown in relationship that comes from lecturing, lecturing someone about what they should do or what they're not doing. I think it lessens the impact, it increases the responsibility of the athlete to his improvement or her improvement and I think that brings the responsibility back fairly squarely where it belongs-with the athlete. I mean the coach at the end of the day is a resource. .. It's more of a mentoring role, it's more of a resource provider that you can set up the structure of sessions that will lead towards certain outcomes and then it's up to the individual to get out of it what they're capable of getting out of it.

In summary, because constraint-led coaching is based on concepts such as self organisation under constraints and encourages exploration via unconscious learning, relatedness is enhanced as the approach promotes a more equal partnership where coach and athlete work together for the benefit of the performer. This shift in emphasis underpins a view that coaching should be based on a process of co-constructed adaptation of the athlete to the challenge of their system of expertise (shared with coach) in order to become successful.

\section{Developing Relatedness in Teams}

Many of the most important decisions made in our world are arrived at not by individuals working in isolation, but by collectives working in unison [48]. Like teams in domains 
such as business or the military, success in team sports is dependent on the best co-ordination and use of the resources available. However, unless coaches deliberately promote mutual understanding of the roles, goals and responsibilities [49] it is highly unlikely that team members will truly understand how best to work together to achieve success. Traditional approaches to developing the elusive 'team spirit' seem to be to about creating proximity, promoting 'teambuilding' via social activities or by taking the team out of their traditional practice environment and requiring them to work together to solve problems (e.g., [50]). However, at present there are few documented examples of how coaches enhance relatedness via the design of learning tasks actually within practice sessions.

A key feature of NLP is the use of representative smallsided games in practice to facilitate the self organising processes inherent in teams (e.g., [7, 51]). Being part of a small team increases the importance of individual contributions from team members and can act to enhance feelings of relatedness towards fellow group members [52]. By focussing on small-sided games, coaches could promote relatedness by creating a climate where players understand their mutual obligation to help and support one another in the pursuit of individual and group goals. Developing the concept of "if you get better, I get better" is mutually beneficial and creates attitudes in practice that are about continual improvement. Additionally, it enhances social support and attraction among teammates and thereby enhances cohesion and commitment to the team [53]. Clearly, for individuals in teams to 'get better' requires exposure to appropriate challenges both in practice as well as in competition. Essentially team-mates need to co-operate by competing to the best of their ability in all practice sessions $[50,54]$. Team dynamics only permit the demonstration of high order skills where all team members are involved and directed towards a common goal. Great tennis for example can only emerge from both players performing well. It is a struggle to generate conditions whereby players discount opportunities to demonstrate individual competence at the expense of their team-mates, in favour of collectively pursuing higher order acts of competence that reflect mutuality in performance. This idea fits well with NLP and Hopper's [21] concept of creating a level playing field by modifying constraints enabling players to be challenged even when they are not of comparable ability. It also corresponds with Jackson's [55] appeal to a higher purpose.

The most effective way to forge a winning team is to call on the players' need to connect to something larger than themselves. Even for those who don't consider themselves 'spiritual' in a conventional sense, ..... It requires the individuals involved to surrender their self-interest for the greater good so that the whole adds up to more than the sum of its parts". Spiritual Lessons of a Hardwood Warrior Sacred Hoops.

Irrespective of standard, all teams have players with different strengths and weaknesses and designing practice tasks that challenge every individual is difficult. Below we provide some ideas that would facilitate relatedness in groups by adopting the ideas of co-operation through competition.
An often over-looked aspect of sports coaching is the development of mental skills such as commitment and communication, confidence, control and concentration. Harwood and colleagues [56] propose that as well as having technical, physical and tactical goals, every coaching session should have a 'psychological' goal. Psychological goals need not be made explicit to learners but they do need to be built into the design of sessions. What is proposed here is a focus on the antecedents of intrinsic motivation; autonomy, competence and relatedness. A broader point is that affective states are constraints and therefore demand equal consideration as part of the learning environment. As such, structuring sessions to promote communication skills and enhance relatedness can create a positive psychological climate for learning [56].

Importantly, tasks that develop communication skills must be perceived as worthwhile by group members and be a key precursor in enabling achievement of their goals. For example, a coach can design a session that is based on developing communication skills to share key information about the abilities of team members and opponents in smallsided games. An example of such a session for football is provided below (see Table $\mathbf{1}$ and Fig. 1). Essentially, the session provides opportunities to develop attunement to opponent's action capabilities and then share this information to provide strategy advice for team-mates. Of course, it must be acknowledged that an individual's action capabilities are co-dependent on those of opponents, and highlights the usefulness of undertaking this session within a squad training session before playing against others. Additionally, we would recommend matching opponents based on skills and capabilities rather than size. In terms of the motivational impact of adopting these ideas, receiving feedback from team mates that focus on strengths and provides advice about the weaknesses of future opponents is likely to enhance perceptions of competence as well as relatedness and autonomy as responsibility for performance is in the hands of the performers.

\section{Backyard Roolz: Adapting the Principles of Backyard Games to Promote Competence, Autonomy and Related- ness}

Backyard Games is a term used to describe informal games typically played by children in the backyard, parks or streets. In other work it has been proposed that the low pressure, fun environment created by backyard games has provided the environment that has been the foundation for many future great sport performers [30, 57, 58]. It is believed that backyard games allow young players to spend time developing often unique skills, requisite mental toughness and the physical conditioning that underpins expertise [30, 57-59].

From the perspective of this paper, backyard games meet many of the needs required to develop intrinsic motivation in performers. Key advantages of backyard games include (most importantly) the absence of adult coaches or parents and promote the active facilitation of positive experiences for all participants. These constraints mean that children (typically) are free to experiment and make mistakes without fear of adult criticism. No backyard game ever results in one sided contests as participants modify rules to make sure that 


\section{Table 1. Session Outline for Promoting Communication Skills in Small-Sided Games}

Session Aims: To develop communication skills between team members to facilitate individual 'exploration' of performance and action capabilities of self, team-mates and opponents to facilitate group goals.

Task: Football (squad of 16 for a 90 minute session). Normal football rules apply. Scoring is in line with standard football rules in that the the aim is to get the ball into the modified goal. If a ball is kicked out, the opponent restarts by dribbling the ball back into play. After a goal, the defender restarts play by dribbling the ball from his/her own goal. The player without the ball must retreat to his goal.

Group Organisation: Organize the group into 4 teams of 4 . The session takes the form of a competition where each team is paired with an opponent. For each competition there are 3 'rounds' and the winning team is the one that wins the most rounds. In Round 1, each team member will play $41 \mathrm{v} 1$ games, in Round 2: 2, 2 v 2 games and in Round 3: One 4 v 4 game. Each round is explained below.

Round One: Teams play $1 \mathrm{v} 1$ games so that each player in the team plays against one of his opponents in a shared area as shown in Fig. (1). The goal is to score in the opponent goal by passing the ball between the posts. Each game will last 3 minutes with a 5 minutes de-brief between each set of games.

Game Organisation (see Fig. 1): Games will take place on a 30 x 20 m pitch. Portable pop-up goals are placed on the 'touchline' of each pitch. For each game, goals should be diagonally placed on opposite lines for each sub-game. Scoring is by 'passing' the ball into the opponent's goal. Order of Games is as follows:

\begin{tabular}{|c|c|c|c|c|c|c|c|}
\hline Game 1 (1 Point Win) & Score & Game 2(2 Point Win) & Score & Game 3 (3 Point Win) & Score & Game 4 (4 Point Win) & Score \\
\hline $1 \mathrm{v} \mathrm{O} 1$ & & $1 \mathrm{v} \mathrm{O} 2$ & & $1 \mathrm{v} \mathrm{O} 3$ & & $1 \mathrm{v} \mathrm{O} 4$ & \\
\hline 3 v O3 & & $3 \mathrm{v} \mathrm{O} 4$ & & 3 v O1 & & $3 \mathrm{v} O 2$ & \\
\hline $4 \mathrm{v} \mathrm{O} 4$ & & $4 \mathrm{v} \mathrm{O} 1$ & & $4 \mathrm{v} \mathrm{O} 2$ & & $4 \mathrm{v} O 3$ & \\
\hline
\end{tabular}

Between rounds: After the first game, each player is encouraged to identify the relative strengths and weaknesses of the opponent he/she played against in that round (e.g.O1 = opponent 1, O2, O3 or O4) and share his/her findings with the team-mate who plays against the opponent in the next round. Typically, comment is made on footedness, ability to turn, speed or susceptibility to specific 'tricks'. After each subsequent round, the process involves all players who have played against a specific opponent sharing information with his next opponent (i.e., in round 3, players 1 \& 4 will brief player 3 who faces O1 next, in round 4 , players 1,4 \& 3 will brief player 2 who is due to face O1).

Scoring: In order to reward good informative communication a win in each subsequent round is awarded more points. That is, round 1 is worth 1 point, round 2, 2 points and so on. The team with most points at the end of all games wins the round and is awarded 1 point to go to the final score.

Round Two:

Teams play 2 v 2 games so that each pair plays against each of the opponents pairs. Games will be 6 minutes long ( 2 x 3 minute halves). 6 minutes between halves, with 5 minutes between each round of games. 2 pop-up goals are positioned adjacent to each other opposite the opponent's goals. Thus, 2 games play 'across' each other.

\begin{tabular}{|c|c|c|c|}
\hline Game $\mathbf{5}$ (2 Points for a Win) & Score & Game 6 (4 Points for a Win) & Score \\
\hline \hline $1+2$ v O1+O2 & & $1+2$ v O3+O4 & $3+4$ v O1+O2 \\
\hline $3+4$ v O3+O4 & & & \\
\hline
\end{tabular}

Between rounds: After the first game, each pair brief their team-mates to identify the relative strengths and weaknesses of the opposing pair they are due to play. Advanced facilitation would require examination not only of weaknesses in individuals but how those weaknesses are reflected in competitive tasks.

Scoring: In order to reward good communication a win in the second round of games is awarded more points. That is, round 1 is worth 2 points, round 2, 4 points. The team with most points at the end of all games wins the round and is awarded 2 point to go to the final score.

\section{Round Three:}

Teams play one 4 v 4 game. Games will be 10 minutes long ( 2 x 5 minute halves) with 5 minutes communication time between each half. A 'big' goal is positioned at opposite ends of the field as per normal football rules. Before the start of the game, each team will have 10 minutes to pool the information they have gained from the earlier rounds enabling them to come up with a strategy to win the final game. To emphasise the importance of communicating and sharing information from the previous rounds, the final round is worth 3 points. This means that a team who has lost the previous 2 rounds of games can still achieve a draw and send the competition into a 2 minute play-off.

Advanced facilitation here would require examination not only of weaknesses but deliberate use of team strategies to exploit them.

\begin{tabular}{|c|c|}
\hline Round 3 (Game 7) (2 Points for a Win) & Score \\
\hline \hline $1+2+3+4$ v $\mathrm{O} 1+\mathrm{O} 2+\mathrm{O} 3+\mathrm{O} 4$ & \\
\hline
\end{tabular}

\section{Final Score:}

\begin{tabular}{|c|c|c|c|}
\hline FINAL SCORE & Round 1 & Round 2 & Round 3 \\
\hline \hline (Possibilities) & $1-0$ OR 0-1 & 2-0 OR 1-1 & $5-0$ or 4-1 or 1-4 \\
\hline
\end{tabular}



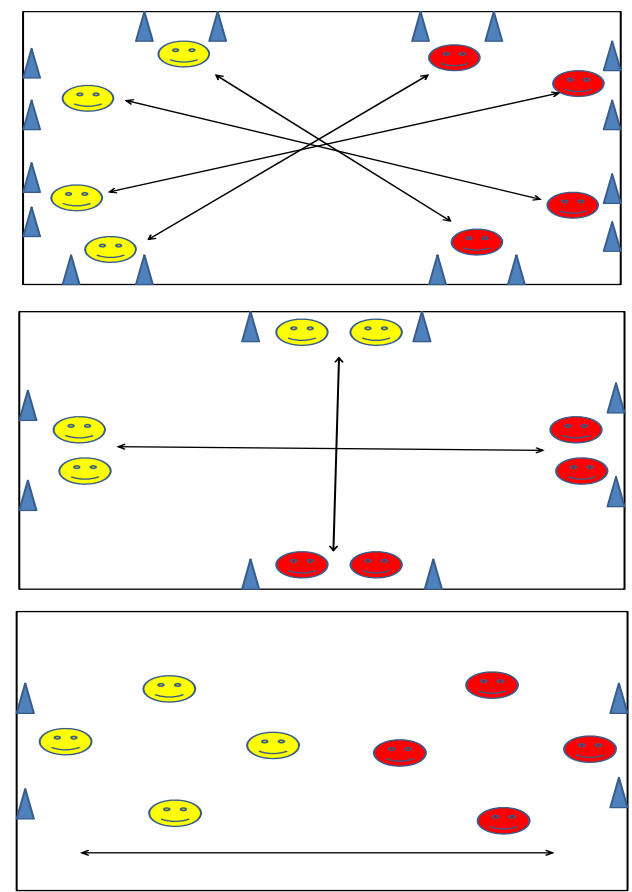

Fig. (1). (a) Round 1: Four, 1 v 1 Games, (b) Round 2: Two, 2 v 2 games and (c) Round 3: One, 4 v 4 Game.

equity occurs and acknowledgment of individual differences in competence is built into game rules. As such, equity is almost guaranteed in every backyard game, because if a game does become one-sided, individuals who do not achieve personal goals will leave. In essence it is in player's interests to promote participation! Often backyard games involve groups who are of different ages, sizes and abilities and consequently rules are adjusted so that each individual gets a 'fair go' and tasks that are appropriate to their ability level. This means that negotiation of modified rules for indi viduals is essential if games are to meet the needs of all players. Of course, by their very nature, backyard rules are flexible and specific to the environment in which the game is played. Autonomy is promoted via back yard games as individuals develop their own solutions to problems and rules and disputes are negotiated with fairness and maximal participation central to the process [58].

Given the psychological and skill acquisition advantages of the backyard game concept highlighted previously [30], an interesting question is why coaches have not adapted the ideas into coaching practice. One reason is that the terms "coaching” and "practice" bring up connotations of organisation and formality where the expectation is that the coach will “"teach" or" instruct” [60]. We would counter this viewpoint by emphasizing that contemporary skill learning theory such as the constraint-led approach highlights that an "organized" session can be carefully planned to be "unstructured" to facilitate discovery learning. Below we provide exemplars of the rules that we would suggest are fundamental to any game-irrespective of the context of being included in a formal coaching programme, or when played by children in the backyard, street or playground.

\section{Basic Game Rules}

1. No uneven games. Once a game becomes uneven (e.g., more than a 3 goal difference) the rules are modified to make the game even. This should be done by negotiation between the 2 teams. Possible changes include:

a. Player exchanges between teams.

b. Rules changed to make it harder for one team or easier for the other.

c. Changing equipment (e.g., using a different ball, different bat widths in striking and fielding games).

d. Some players get more points for scoring, or the team gets more points if a specific player contributes to a score.

2. Rules are modified for individuals, i.e., harder for the better players, easier for the less skilled.

a. Best batters use a 'thin' bat, have to face a taped ball that 'swings'

b. Best players restricted on touches or can only play passes with the weaker foot or to the weak hand side.

3. Co-operative Rules can apply to paired players (player A from Team 1 and player B from Team 2).

a. For example, in a $4 \mathrm{v} 4$ small ball passing game, the coach can provide the following rules:

I. Player 1: Must catch with strongest hand

II. Players 2/3: Can catch with 2 hands

III. Player 4: Must catch with weaker hand

To summarize, although, individualization is a key coaching principle it is often poorly implemented, particularly in team sports [61]. This challenge can be overcome by underpinning learning design with SDT and NLP to think creatively, like children do in the backyard. Coaches can base session design on individual action capabilities enabling the appropriate goals to be set for each individual. Engaging with the group by involving them in making decisions about 
task activities would also promote relatedness and autonomy. Through promoting a strategy of self-regulated learning within a mastery climate, the needs of each individual can be met and hence perceptions of competence are also enhanced $[21,62]$. In the next section we discuss how the ideas presented in this section can be merged with some new ideas in skill acquisition to design effective practice tasks for high level performers that promote perceptions of competence.

\section{REPRESENTATIVE PRACTICE DESIGN: BATTLE ZONES}

Basing training on games is a key feature of a NLP. As highlighted earlier, the key to game design is adopting the principles of representative learning design [35]. Essentially, practice tasks must lead to the acquisition of functional behaviours for competition. In order to do this, coaches must ensure that the constraints of training and practice adequately replicate the performance environment, ensuring learners are able to couple actions to key information sources. Practicing in environments that seek to replicate competition environments provides multiple opportunities for holistic development and facilitates attunement to specifying information sources. By adopting the principle of repetition without repetition, coaches provide opportunities to attempt to achieve a consistent performance outcome, but the way that this goal is achieved would not be repeated in an identical way every time, promoting functional adaptability to cope with variable challenges (see [6]). In terms of the impact of this approach on the self determining behaviours of performers, by manipulating constraints coaches can enhance perceptions of competence by providing opportunities to experience success in tasks that are just like the real game, such as making the last shot to win in basketball, serving to save the set in tennis, or playing against superior opponents in challenging physical environments in team games.

An often missing factor in learning design and perhaps a key challenge for coaches is making the practice environment as emotionally and psychologically engaging as the competition environment. Although it is worth noting that a characteristic of some top athletes appears to be that they are able to create their own intensity by 'competing' as they would in competition in every training session (see [54]) it is not uncommon for coaches to observe many performers simply going through the motions during the monotony of repetitive training tasks (see page 3 of this paper). How then can coaches create 'emotional engagement' in learning tasks? Essentially, the coach needs to create a motivational climate that is about self improvement. As highlighted earlier, a climate needs to be created where squad members embrace the idea that they can only get better if they work co-operatively by competing as hard as they can during practice sessions. As Clive Woodward, coach to the 2003 World Cup Winning England Rugby Union team suggests 'there is nothing like a game to truly ignite the competitive spirit of high-performance athletes' [50]. Recently, we captured this love of games in the development of a new approach to the training of elite cricketers, introducing the concept of "The Battle Zone" at the Cricket Australia/AIS Centre of Excellence in Brisbane [63]. Various games were designed to provide players with representative practice tasks where they were faced with challenges they would face in 'real' com- petitive games. Although no empirical measures were used to assess player's psychological engagement when playing Battle Zone games, it was clear to coaches and support staff that the majority of the players were emotionally and psychologically engaged at levels commensurate to those portrayed in real competitive games.

\section{Protecting Competence: The Difference between Setting Learners Up to Learn as Opposed to Setting Them Up to Fail}

Three important risks need to be considered with respect to learning designs that reflect the principles outlined in the previous sections. First, challenge in itself does not automatically lead to learning and constant challenge may risk undermining long-term feelings of competence. If learners are to learn from mistakes it makes sense that practice designs force learners to make learning appropriate errors. Adopting such thinking requires a significant shift for many coaches and highlights the need to see mistakes a normal part of the learning process [7, 64]. Often coaches do this by stretching the limits of an existing skill or increasing the level of difficulty within a task. For example, passing practice might start with players being close together and then the distance between players will gradually be increased to the point where the passing skill fails. The first point here is that challenge starts from a point of competence (i.e., something learners can do). The second issue is that the point of failure needs to be supported with suitable reflection by the player(s) if they are to develop new skills and/or a clear understanding of the boundaries of existing skills. This is not automatic and needs to be facilitated by coaches. The third issue is that practice has to return to a point of competence in order for performers to recognise what they have learned and how much they have achieved.

Studies examining the development of expert performers have revealed that young performers get to play up and then play down during their developmental career [65]. Thus, a young cyclist may be entered into an adult race then allowed to return to junior racing. This idea can be expanded on by setting clear (soft) goals before playing up, not playing up for too long and carefully reflecting on the two different states of performance in order to plan future training.

\section{Hands-off Coaching and Autonomy: A Double Edged Sword?}

The constraint-led approach sees the skill fit the learner and practice tasks supporting that process. This allows learners to engage in decision-making to find a task solution that is founded in their own understanding of the problem. By simply telling players what you want them to do rather than telling them how to do it and then adopting the concept of repetition without repetition to enable multiple practice trials (see [7]), gives players the freedom to find solutions to performance problems through exploration. Such an approach permits players to enjoy solving problems and develop unique solutions that meet both internal (i.e. autonomy, competence, relatedness) and external constraints (i.e., goals related to performance). This does not mean that all decisions should be in the hands of the learner: basic boundaries may be grounded in perception, movement and competence. 
In terms of perceptual skills, inexperienced learners struggle to understand principles of games and perceiving the relevant informational cues to make the right decisions is difficult often leading to decisions being based on less appropriate cues [66]. An example of this may be seen where novice players try and watch an approaching tackler when about to catch a high ball in rugby; inevitably they miss or fumble the catch. With respect to actions, an excessive focus on outcome can lead to short-term gains at the expense of appropriate technique [67]. For example, well-practiced but uncoached basketball players are often easy to spot because they shoot the ball with a flat trajectory, which is successful early in learning but not at an expert level. Finally, simply allowing performers to make all performance decisions is not necessarily empowering or intrinsically motivating [68]. Unless the decisions made actually result in enhanced feelings of competence, having autonomy could potentially have negative consequences. For coaches it is important to understand that performers can only make competence endorsing decisions based on what they understand, particularly with respect to outcomes. Not knowing which option to choose is likely to result in anxiety. Making a choice but being uncertain about success criteria will be unrewarding. The coach can help facilitate this process by asking questions about what was learned from the previous trial or prompting the player to consider different cues in the learning context to help make decisions on actions.

When designing tasks to develop decision-making skills the coach must start from an understanding of the action capabilities of each player. Knowledge of player capabilities should then inform the choices available. As such, coaches have to provide boundaries to help shape decision-making by individualizing the choices offered to players in line with their current action capabilities. For example, a football coach may give experienced player A, who has a high level of game understanding and a wide range of technical skills more choices in terms of who to pass to than the less experienced and lower skilled player. These challenges highlight the importance of coaches manipulating practice constraints to match the action capabilities of each performer thereby facilitating guided discovery. In the next section we consider how coaches can design practice that focuses on enhancing the individuals perceptions of autonomy.

\section{Providing Autonomy in Practice Tasks}

When young people are left to themselves to learn sport skills-without coaches, peer pressure or spectators-they have an ingenious way of avoiding failure. Each time they do not obtain their goals, they simply lower them slightly, learn from their mistakes and try again. A few practices and adjustments like these and success is virtually guaranteed...children tend to keep their goals near the upper limits of their current ability ([3], p.129).

In line with the principles of NLP, coaches need to be engaged in a process that reconciles the difficulty of a task with the action possibilities afforded by the learner. This should be achieved by varying the degree of problem solving and decision making during practice. From a motivational point of view, allowing players the autonomy to make practice choices is much more intrinsically motivating than the coach simply prescribing training activities. Dwyer [69] amongst others has demonstrated that merely the perception of choice can improve one's feelings towards a particular activity. Where learners do not get to choose, full engagement with the task is unlikely to occur, e.g., "this is far too easy for me, I am better than the coach thinks I am” (and they might be right). This failure of engagement will lead to poorer goal setting, limited problem solving and therefore task matching is a necessary part of the learning process. This is particularly the case with respect to younger performers where perceptions of competence can change rapidly.

A demonstration of how coaches can design a practice session to enhance perceptions of competence through autonomy, by engaging learners in making choices about their training tasks could be shooting practice in basketball. For example, a basketball coach could provide 5 shooting distances (e.g., $1 \mathrm{~m}, 2 \mathrm{~m}, 3 \mathrm{~m}, 4 \mathrm{~m}, 5 \mathrm{~m}$ ) and require players to complete 5 sets of 10 shots. Rather than directing the players to shoot from each distance in turn, the coach allows each player to initially choose the distance of their own choice for the first set of 10. An important conversation in advance of this session is to find out what the players believe represents mastery of a task. For example, do they believe that a player needs to score 10 out of 10 to demonstrate mastery, or would 7 or 8 out of 10 be sufficient? Similarly, what score would mean that the task was too hard? The answers to these questions then underpin the implementation of rules that determine if a player repeats the set from the same distance or moves nearer or further away for subsequent sets. For example, the players and coach may decide that if a player scores 4 or less out of 10 , they should move 'closer' for the next set, 5-7/10 means they would stay at the same distance, while a score of 8 or above means they move 'up' to the next distance. In the next shooting practice session, the player would start on the distance where they finished the previous session. In our worked example, a typical session for a team

\begin{tabular}{|c|c|c|c|c|c|c|c|c|c|c|}
\hline Player & \multicolumn{2}{|c|}{ Set 1} & \multicolumn{2}{|c|}{ Set 2} & \multicolumn{2}{|c|}{ Set 3} & \multicolumn{2}{|c|}{ Set 4} & \multicolumn{2}{|c|}{ Set 5} \\
\hline Player 2 & $4 m$ & $3 / 10$ & $3 m$ & $4 / 10$ & $2 m$ & $6 / 10$ & $2 m$ & $7 / 10$ & $2 \mathrm{~m}$ & $6 / 10$ \\
\hline Player 3 & $3 m$ & $5 / 10$ & $3 m$ & $6 / 10$ & $3 m$ & $8 / 10$ & $4 \mathrm{~m}$ & $5 / 10$ & $4 \mathrm{~m}$ & $6 / 10$ \\
\hline Player 4 & $2 m$ & $7 / 10$ & $2 \mathrm{~m}$ & $5 / 10$ & $2 m$ & $4 / 10$ & $1 \mathrm{~m}$ & $8 / 10$ & $2 m$ & $5 / 10$ \\
\hline
\end{tabular}

Fig. (2). Example scoring process for set shot in basket ball. 
(5 examples from a squad of 10) could look like something like Fig. (2):

In our example, player 1 obviously chose an 'easy' challenge $(1 \mathrm{~m})$ that was below his skill level and moved immediately to $2 \mathrm{~m}$, which was also relatively easy, before finding his/her appropriate challenge at 'level' at 3m. Conversely, player 2 chose an initial task that was much too hard for his ability level (4m) and moved to $3 \mathrm{~m}(4 / 10)$ and then settled at the $2 \mathrm{~m}$ level by the third set. Players $3 \& 4$ could be said to have judged their ability level about right as they achieved moderate scores in their first two sets. In contrast, in the last three set, player 3 improved, while player 4 dropped down a level before bouncing back up in the last set. Player 5 is clearly the best shooter and spends his time practicing shooting from 4 and $5 \mathrm{~m}$ and very soon would be likely to need to be provided with more challenging tasks.

Worth noting in the design of this session is the need to create shooting practice that is realistic in developing perception and action coupling [7]. Players should therefore work in pairs with one member of the pair acting as a defender who attempts to 'block' the shot. Coaches (in consultation with the players) can manipulate the distance that the defender stands in front of the shooter. An additional constraint could be for the defender to retrieve rebounds from shots and immediately pass the ball to the defender before closing them down (walking/jogging/running), which imposes gamelike time constraints. Furthermore, care needs to be applied with respect to session designs that support the learner and encourage variability. While a session may begin with some blocked practice (simple repetition of a skill) it should include variability as soon as is reasonable which will provoke mistakes. The coach has a role supporting players in this process, creating the understanding that mistakes are a normal part of the learning process $([3,6,7,60])$. It is also quite valid to return learners to blocked practice in the same session so that they may recognise what has been achieved in order to support feelings of competence.

\section{SUMMARY}

We have sought to integrate motivational theories with NLP and in particular constraints-led approaches to coaching. We have shown through worked examples how coaches can embed opportunities to promote relatedness, competence and autonomy within an NLP framework. Although many of the examples have referred to team games, these principles apply equally to individual sports. In line with Orlick \& Botterill [60] we suggest that sport programmes seeking to develop skilled performers shift focus away from drill based learning to a more hands-off coaching approach supported by NLP. This approach emphasises (guided) discovery learning along with the mutuality of co-operation and competition. Furthermore, making mistakes needs to be positioned as an opportunity to learn, therefore reinforcing feelings of competence, autonomy and relatedness. What should be avoided are mistakes being used as devices for creating pressuring or controlling learners for short-term motivational gains. This approach clearly does not mean performers should go unchallenged; rather that challenge is supported and contributes to a long-term desire to be involved. Whatever the level of the performers, there needs to be inherent fun in practice sessions (see $[50,60])$. This point is critical given the views of Hennessey, [70]:

I have come to hypothesize that the reduction of intrinsic interest in young children (and perhaps all of us) is driven primarily by the learned expectation that rewards are usually paired with activities that need to be doneactivities that are often not fun and sometimes even aversive. The undermining of intrinsic interest may result as much from emotion or affect as it does from cognitive analysis. Children may learn to react negatively to a task as "work" when their behavior is controlled by socially imposed factors (such as rewards), and they may react positively to a task as "play" when there are no constraints imposed [70].

The presence of the coach should add value to the process of becoming skillful in particular it should not subtract from the desire for self organized play in children. At youth level, the potential added value brought to sport by coaches in terms of enhancing performance should be exactly that, not a transfer of values that sees the drive for performance results interfere with long-term sport engagement. At more senior levels where the pressure to win is perhaps more intense, we would emphasise that a long career is a successful one. Consequently, creating environments that are intrinsically motivating are still more likely to lead to the achievement of desired goals for all involved. Essentially, all sport performers irrespective of ability will be more persistent and committed to improvement if coaches design programmes that facilitate intrinsic motivation.

\section{CONFLICT OF INTEREST}

The authors confirm that this article content has no conflicts of interest.

\section{ACKNOWLEDGEMENT}

Declared none.

\section{REFERENCES}

[1] Ericsson KA, Krampe RT, Tesch-Romer C. The role of deliberate practice in the acquisition of expert performance. Psychol Rev 1993: 100(3); 363-406.

[2] Mitchell SA, Oslin JL, Griffin LL. Teaching sport concepts and skills: a tactical games approach. Champaign: Human Kinetics 2006: vol. 1.

[3] Martens R. Successful coaching. $3^{\text {rd }}$ ed. Champaign: Human Kinetics 2004.

[4] Thorpe R. Rod Thorpe on teaching games for understanding. In: Kidman L, Ed. Athlete-centred coaching: Developing inspired and inspiring people. Christchurch: Innovative Print Communication Ltd 2005: pp. 229-43.

[5] Deci EL, Ryan RM. The "what" and "why" of goal pursuits: Human needs and the self-determination of behavior. Psychol Inq 2000: 11(4); 227-68.

[6] Renshaw I, Davids K, Chow J, Shuttleworth R. Insights from ecological psychology and dynamical systems theory can underpin a philosophy of coaching. Int J Sport Psychol 2009; 40: 580- 602.

[7] Renshaw I, Chow JY, Davids K. Hammond J. A constraints-led perspective to understanding skill acquisition and game play: a basis for integration of motor learning theory and physical education praxis? Phys Educ Sport Pedagogy 2010; 15(2): 117-37.

[8] Chow JY, Davids K, Button C, Shuttleworth R, Renshaw I, Araújo D. Nonlinear pedagogy: a constraints-led framework to understand emergence of game play and skills. Nonlinear Dynamics Psychol Life Sci 2006; 10 (1): 74-104. 
[9] Chow JY, Davids K, Button C, Shuttlewort, R, Renshaw I, Araújo D. The role of nonlinear pedagogy in physical education. Rev Educ Res 2007; 77(3): 251-78.

[10] Davids K, Button C, Bennett, SJ. Coordination and control of movement in sport: an ecological approach. Champaign, IL: Human Kinetics 2008.

[11] Deci EL, Ryan RM. Self-Determination Theory. 2011. Available from: http://www.psych.rochester.edu/SDT/theory.php

[12] Baumeister RF, Leary MR. The need to belong: desire for interpersonal attachments as a fundamental human-motivation. Psychol Bull 1995; 117(3): 497-529.

[13] Reis HT, Sheldon KM, Gable SL, Roscoe J, Ryan RM. Daily wellbeing: the role of autonomy, competence, and relatedness. Person Soc Psychol Bull 2000; 26: 419-35.

[14] Ryan RM, Deci EL. The darker and brighter sides of human existence: basic psychological needs as a unifying concept. Psychol Inq 2000; 11(4): 319-38.

[15] Harter S. Pleasure derived from challenge and effects of receiving grades on children's difficulty level. Child Dev 1978; 49(3): 78899.

[16] White RW. Motivation reconsidered: the concept of competence. Psychol Rev 1959: 66; 297-333.

[17] Deci EL, Ryan RM. The empirical exploration of intrinsic motivational processes. In: Berkowitz L, Ed. Advances in experimental social psychology. New York: Academic 1980; vol. 13, pp. 39-80.

[18] Deci EL, Ryan RM. Intrinsic motivation and self-determination in human behavior. New York: Plenum 1985.

[19] Bartholomew KJ, Ntoumanis N, Ryan RM, Thogersen-Ntoumani C. Psychological need thwarting in the sport context: assessing the darker side of athletic experience. J Sport Exerc Psychol 2011; 33(1): 75-102.

[20] Kyllo LB, Landers DM. Goal setting in sport and exercise: a research synthesis to resolve the controversy. J Sport Exerc Psychol 1995; 17(2):117-37.

[21] Hopper T. Game-as-teacher: modification by adaptation in learning through game-play. Asia-Pacific J Health Sport Phys Ed 2011; 2(2):18-22.

[22] De Charms R. Personal causation: the internal affective determinants of behavior. New York: Academic Press 1968; pp. 272-4.

[23] Deci EL. Intrinsic motivation. New York: Plenum Publishing Company 1975.

[24] Deci EL, Vansteenkiste M. Self-determination theory and basic need satisfaction: understanding human development in positive psychology. Ricerche di Psichologia 2004; 27: 17-34.

[25] Ryan RM, Deci EL, Grolnick WS. Autonomy, relatedness and the self: their relation to development and psychopathology. In: Cicchetti D, Cohen D J, Eds. Developmental psychopathology: theory and methods. New York: Wiley 1995; pp. 618-55.

[26] Chow J, Davids K, Button C, Renshaw I, Shuttleworth R, Uehara L. Nonlinear pedagogy: implications for teaching games for understanding (TGfU). In: Hopper T, Butler J, Storey B, Eds. TGfU. Simply good pedagogy: understanding a complex challenge. Canada: Ottawa: Physical Health Education Association. 2009.

[27] Davids K, Bennett S, Newell KM, Ed. Movement system variability. Champaign. Illinois: Human Kinetics 2006.

[28] Newell KM. Constraints on the development of coordination. In: Wade MG, Whiting HTA, Eds. Motor development in children. Aspects of coordination and control. Dordrecht. Netherlands: Martinus Nijhoff 1986; pp. 341-60.

[29] Passos P, Araújo D, Davids K, Shuttleworth R. Manipulating constraints to train decision making in rugby union. Int J Sport Sci Coach 2008; 3: 125-40.

[30] Renshaw I, Chappell GS. A constraints-led approach to talent development in cricket. In: Kidman L, Lombardo B. Eds. Athletecentred coaching: developing decision makers $2^{\text {nd }}$ ed. Worcester: IPC Print Resources 2010; pp. 151-73.

[31] Bernstein NA. The Control and Regulation of Movements. London: Pergamon Press 1967.

[32] Beek PJ. Toward a theory of implicit learning in the perceptual motor domain. Int J Sport Psychol 2000; 31: 547-54.

[33] Jackson RC, Farrow D. Implicit perceptual training: how, when and why? Hum Mov Stud 2005; 24(3): 308-25.

[34] Masters R, Law J, Maxwell J. Implicit and explicit learning in interceptive actions. In: Davids K, Savelsbergh G, Bennett SJ, van der Kamp J, Eds. Interceptive actions in sport: information and movement. New York: Routledge 2002; pp. 126-43.

[35] Pinder RA, Davids K, Renshaw I, Araújo D. Representative learning design and functionality of research and practice in sport. J Sport Exerc Psychol 2011; 33: 146-55.

[36] Pinder RA, Renshaw I, Davids K, Golds T. Information-movement coupling in developing cricketers under changing ecological practice constraints. Hum Move Sci 2009; 28: 468-79.

[37] Renshaw I, Oldham ARH, Davids K, Golds T. Changing ecological constraints of practice alters coordination of dynamic interceptive actions. Eur J Sport Sci 2007; 7: 157-67.

[38] Renshaw I, Fairweather MM. Cricket bowling deliveries and the discrimination ability of professional and amateur batters. J Sports Sci 2000; 18: 951-7.

[39] Müller S, Abernethy B. Batting with occluded vision: an in situ examination of the information pick-up and interceptive skills of high- and low-skilled cricket batsmen. J Sci Med Sport 2006; 9(6): 446-58.

[40] Smith T. Development as a dynamic system. Trends Cognitive Sci 2003; 7(8): 343-8.

[41] Davids K, Araújo D. The concept of organismic asymmetry. Sport Sci 2010; 13(6): 633-40.

[42] Renshaw I, Davids, K, Phillips, E, Kerherve, H. Developing talent in athletes as complex neurobiological systems. In: Baker J. Schorer J. Eds. Int Perspect in Talent Identification. UK: Routledge 2011.

[43] Chow J-Y, Davids K, Hristovski R, Araújo D, Passos P. Nonlinear Pedagogy: learning design for self-organizing neurobiological systems. New Ideas Psychol 2011; 29: 189-200.

[44] Lyle J. Sports coaching concepts: a framework for coaches behaviour. London: Routledge 2002.

[45] Sagar SS, Lavallee D, Spray C. Why young athletes fear failure: consequences of failure. J Sports Sci 2007; 25, 1171-84.

[46] Gould D, Guinan D, Greenleaf C, Medbery R, Peterson K. Factors affecting Olympic performance: perceptions of athletes and coaches from more and less successful teams. Sport Psychol 1999; 13(4): 371-94.

[47] Sagar SS, Stoeber J. Perfectionism, fear of failure and affective responses to success and failure: the central role of fear of experiencing shame and embarrassment. J Sport Exerc Psychol 2009; 31: 602-27.

[48] Bonner BL. Expertise in group problem solving: recognition, social combination and performance. Group Dyn: Theory Res Pract 2004; 8(4): 277-90.

[49] Jowett S.Coach-athlete relationships ignite a sense of groupness. In: Mark R, Beauchamp MR, Eys MA, Eds. Group Dynamics in Exercise and Sport Psychology. Contemporary Themes Abingdon. UK: Routledge 2007; pp. 63-76.

[50] Woodward C, Potanin F. Winning. London: Hodder \& Stoughton 2005.

[51] Passos P, Araujo D, Davids KW, Shuttleworth R. Manipulating task constraints to improve tactical knowledge and collective decision-making in rugby union. In: Renshaw I, Davids KW, Savelsbergh GJP, Eds. Motor Learning in Practice: a ConstraintsLed Approach. London: Routledge 2010; pp. 120-30.

[52] Renshaw I, Moy B. Adopting a theoretically driven approach to learning design changes student's beliefs in how to teach P.E. AISEP 2011: International Association of Physical Education in Higher Education International Conference; 22-25th June 2011; University of Limerick. Limerick: Ireland 2011.

[53] Smith RE, Smoll FL. Coaching the coaches: youth sports as a scientific and applied behavioural setting. Curr Dir Psychol Sci 1997; 6(1):16-21.

[54] Warne S. England must retain hunger to remain world's Test No 1 nation following whitewash of India. Daily Teleg 2011 [cited 2011 8th September 2011].

[55] Jackson P, Delehanty H. Sacred hoops: spiritual lessons of a hardwood warrior. New York: Hyperion 1995.

[56] Harwood C. Developing consulting in a professional football academy: The 5Cs coaching efficacy program. Sport Psychol 2008; 22: 109-33.

[57] Cannane S. First tests: great Australian cricketers and the backyards that made them. Sydney: ABC Books 2009.

[58] Cooper P. Play and children. In: Kidman L, Lombardo BJ, Eds. Athlete-centred coaching. Worcester: IPC Print Resources 2010; pp. 37-151. 
[59] Araujo D, Fonseca C, Davids KW, et al. The role of ecological constraints on expertise development. Talent Dev Excell 2010; 2(2):165-79.

[60] Orlick T, Botterill C. Every kid can win. Chicago: Nelson-Hall 1975.

[61] Cross N, Lyle J, Eds. The coaching process. Oxford: Butterworth \& Heinemann 1999.

[62] Hopper T, Sanford K, Clarke A. Game-as-teacher and game-play: complex learning in TGfU and Videogames. In: Hopper T, Butler J, Storey B, Eds. TGfU Simply Good Pedagogy: Understanding a Complex Challenge. Physical Health Education. Ottawa: Canada 2009; pp. 201-12.

[63] Renshaw I, Chappell GS, Fitzgerald D, Davison J. The battle zone: constraint-led coaching in action. Paper presented at the Conference of Science, Medicine \& Coaching in Cricket, Sheraton Mirage, Gold Coast. Queensland: Australia 2010; pp.1-3.
[64] Allpress J. Managing mistakes to the players advantage: lessons from coaching in football (soccer). Dev Learn Org 2006; 20 (4): 69.

[65] Phillips E, Davids K, Renshaw I, Portus M. The development of fast bowling experts in Australian Cricket. Talent Dev Excell 2010; 2(2): 137-48.

[66] Jacobs DM, Michaels CF. On the apparent paradox of learning and realism. Ecolog Psychol 2002; 14(3): 127-39.

[67] Kernodle MW, Carlton LG. Information feedback and the learning of multiple degree of freedom activities. J Mot Behav 1992; 24(2): 187-96.

[68] Mageau GA, Vallerand RJ. The coach-athlete relationship: a motivational model. J Sports Sci 2003; 21: 883-904.

[69] Dwyer JJM. Effect of perceived choice of music on exercise intrinsic motivation. Health Values 1995; 19: 18-26.

[70] Hennessey BA. Self-determination theory and the social psychology of creativity. Psychol Inq 2000; 11(4): 293-8.

Received: September 19, 2011 Revised: May 25, 2012

Accepted: May 30, 2012

(C) Renshaw et al.; Licensee Bentham Open.

This is an open access article licensed under the terms of the Creative Commons Attribution Non-Commercial License (http://creativecommons.org/licenses/ by-nc/3.0/) which permits unrestricted, non-commercial use, distribution and reproduction in any medium, provided the work is properly cited. 